\title{
LIDERANÇA FEMININA NAS ORGANIZAÇÕES: DISCURSOS SOBRE A TRAJETÓRIA DE VIDA E DE CARREIRA DE EXECUTIVAS
}

FEMININE LEADERSHIP IN THE ORGANIZATIONS: SPEECHES ON THE LIFE AND CAREER TRAJECTORY OF EXECUTIVES

\section{RESUMO}

A pesquisa é um estudo qualitativo e exploratório que buscou compreender a percepção de mulheres líderes sobre suas trajetórias profissionais e pessoais a respeito dos desafios vivenciados e estratégias de enfrentamento. Como estratégia de coleta de dados, realizaram-se oito entrevistas narrativas, com cinco executivas de alta administração de diferentes segmentos. A analise de dados foi através da análise de discurso (PÊCHEUX, 1988) do software NVivo. O referencial teórico sustentou-se sob quatro eixos: liderança e a influência de gênero; representações sociais de gênero; história da mulher no mercado de trabalho e em cargos de gestão e, liderança feminina. A pesquisa revelou um ambiente organizacional eminentemente masculino, enfrentamento de tetos de vidro e a necessidade vivenciada pelas mulheres, de comprovar sistematicamente suas competências.

Palavras-chave: Liderança feminina. Trajetórias de vida e de carreira. Organizações.

\begin{abstract}
This qualitative and exploratory study aimed at understanding the perception of women leaders about their professional and personal trajectories about the challenges experienced and coping strategies. As data collection strategy, there were held eight narrative interviews with five top management executives of different industries. Data were analyzed through discourse analysis of the French line and the use of the categorization of data NVivo software. The theoretical framework is maintained under four pillars: leadership and its influence by gender; social representations of gender; history of women in the labor market and in management positions, and women's leadership. The survey revealed an eminently masculine organizational environment, coping with glass ceilings and the need experienced by women to systematically demonstrate their skills.
\end{abstract}

Keywords: female leadership. Trajectories of life and career. Organizations.

\footnotetext{
${ }^{1}$ Mestre pelo Programa de Mestrado Profissional a Unisinos. Experiência internacional através da extensão acadêmica do Mestrado Profissional em Gestão e Negócios - Universidade de Poitiers, França.

${ }^{2}$ Doutora em Psicologia, com tese sobre Liderança e Processo Grupal (PUCRS, 2008), Mestre em Administração de Empresas (PUC-Rio, 1999) e graduada em Psicologia (Universidade do Vale do Rio dos Sinos, 1993). Professora adjunta da Universidade do Vale do Rio dos Sinos.
} 


\section{INTRODUÇÃO}

A temática da liderança é pauta de destaque no universo organizacional, especialmente quando se discute o planejamento e os destinos dos negócios em um mercado intensamente concorrido. No cerne dessa discussão, nos deparamos com diferentes perfis existentes, relações de poder, autoridade e influência, e aspectos gerais no que tange à gestão de pessoas nas empresas, o que faz com que vários estudiosos se dediquem a estudar a liderança, por entendê-la como um dos pontos chaves do sucesso e uma importante vantagem competitiva (BRYMAN, 2012; VRIES, 1997 e 2012). Isso oportuniza a reflexão sobre a participação das mulheres nos cargos de gestão, já que sua entrada no mercado de trabalho foi um dos fenômenos mais importantes ocorridos na sociedade moderna, em parte por necessidades econômicas, mas, também, pela mudança de perfil da mulher que busca sua satisfação fora do domínio do lar e reinventa seu papel na sociedade (BETIOL; TONELLI, 1991).

Ao longo dos tempos, a mulher tem enfrentado inúmeros impasses para alcançar maior participação social, cultural e econômica na sociedade. Conforme Lobos (2002, p. 21), “(...) a história do homem foi escrita por homens e principalmente sobre homens", e no contexto empresarial não é diferente. Apesar dessa situação já haver melhorado consideravelmente, ainda se percebem distorções significativas no que tange à questão de remuneração, de possibilidade de crescimento e de respeito à sua individualidade (VRIES, 2012; STREY, 2000). São unânimes, entre os autores que discutem a liderança feminina, os enfrentamentos de "tetos de vidro" ou "muros de aço" na promoção de mulheres a posições de chefia, além da incipiente participação nas tomadas de decisão organizacionais (LOBOS, 2002).

Nessa linha, o presente artigo, através da questão norteadora "Qual é a compreensão que as mulheres, líderes executivas, têm a respeito de suas trajetórias de vida e de carreira?", pretende discutir a liderança feminina revisitando conceitos arraigados nos discursos sociais, científicos e organizacionais acerca da liderança e do gênero, e entender como estes elementos influenciam na ascensão de mulheres postos de liderança. Além disso, faz-se importante entender como as mulheres percebem e vivenciam possíveis adversidades e como são ditadas pelos paradigmas sociais e culturais vividos ao longo do tempo.

Esse artigo estrutura-se da seguinte forma: inicia por uma rápida contextualização teórica acerca do conceito de liderança, especialmente no que diz respeito à articulação desse a temática do gênero. Sequencialmente, visa compreender como se deu, ao longo dos tempos, a construção das representações sociais em relação à mulher. Em seguida realiza uma breve retomada histórica da trajetória da participação da mulher no mercado de trabalho, e como se deu, nos últimos anos, sua inserção em cargos de gestão, culminando na discussão sobre liderança feminina e relações existentes entre a vida profissional e pessoal nesse recente contexto. Os resultados da pesquisa serão apresentados dentro de três categorias de análise, a saber: trajetória, concepções de liderança e ambiente organizacional, emergentes das entrevistas narrativas realizadas com as executivas participantes do estudo. 


\section{LIDERANÇA: CONCEITOS E CONCEPÇÕES}

O conceito de liderança vem sendo construído ao longo do tempo de acordo com as especificidades sociais e econômicas de cada época e as definições observadas variam desde uma administração marcada pela racionalidade e maximização dos lucros através da eficiência de rotinas organizacionais, até abordagens humanizadas, focadas em aspectos psicossociais relacionados ao desempenho e motivação das pessoas (CAVALCANTI et al., 2006). Esses pressupostos influenciam o entendimento da liderança até os dias de hoje, e oportunizam a problematização acerca das relações de gênero presentes em tais concepções.

Por mais que as conceituações tenham se modificado de forma marcante, ainda se encontram cristalizadas ideias que focam o exercício da liderança em um conjunto de atributos de determinados indivíduos e padrões de comportamento e desempenho. Nessa linha, a teoria dos traços, que foi dominante até o final dos anos 40, defende que algumas características inatas diferenciam os líderes dos liderados, em suas capacidades físicas, sociais e de personalidade, destacando como requisitos essenciais a força física, alto coeficiente de inteligência e considerável capacidade administrativa e de execução de tarefas, colocando o líder em uma posição marcadamente idealizada e padronizada e, ainda associada a características atribuídas socialmente ao masculino e reforçando representações sociais (BRYMAN, 2012; CAVALCANTI et al., 2006; CABRAL; SEMINOTTI, 2009a; TURANO, CAVAZOTTE, 2016).

As teorias comportamentais representam um início de abertura da visão da liderança, pois, apesar de ainda enfatizarem a orientação para as tarefas, já começam a considerar a relação do líder com seus liderados, a partir de um conjunto de comportamentos representados pelo líder, para um atingimento das metas organizacionais (BRYMAN, 2012).

As teorias contingenciais ampliam ainda mais a visão, ultrapassando um pouco a ótica linear para considerar diversas variáveis dentro da realidade da organização; cabendo ao líder direcionar as escolhas e motivar seus funcionários para o alcance de determinados objetivos, influenciando-os positivamente, de acordo com o nível de maturidade destes liderados (CAVALCANTI et al., 2006; CABRAL; SEMINOTTI, 2009a TURANO, CAVAZOTTE, 2016). Essa abordagem enfatiza o fator situacional da liderança e concentra a liderança dentro de uma perspectiva formal, excluindo os fenômenos de lideranças informais (BRYMAN, 2012).

As teorias neocarismáticas, mais contemporâneas, ressaltam o magnetismo, o carisma e a sensibilidade do líder frente às necessidades dos liderados, ultrapassando assim uma visão pragmática para considerar a subjetividade presente no exercício da liderança. A liderança transformacional, dentro da abordagem neocarismática, por exemplo, sustenta em sua perspectiva a importância de características como a bondade, humildade, generosidade do líder, apontando atitudes essências: a atenção individualizada; o estímulo cognitivo; o exemplo e a inspiração do líder bem como o estabelecimento de relações de confiança. (CABRAL; SEMINOTTI, 2009a TURANO, CAVAZOTTE, 2016) 
Outra tendência no contexto atual discute todo o conjunto complexo e dinâmico que envolve a ação da liderança (DeRUE e ASHFORD, 2010; CABRAL; SEMINOTTI, 2009b). Portanto, a liderança se constitui, é mantida e permanentemente modificada a partir da interação social desse líder e pensada dentro de uma perspectiva recursiva. Essa visão pressupõe a importância da ampliação da visão estática da liderança, baseada em padrões de comportamentos elencados no intuito de formular um padrão de sucesso a ser colocado em prática nas empresas. Esse entendimento é um passo importante, já que a liderança deixa de ser o resultado de um conjunto de atributos específicos para centrar-se na capacidade de formação de redes, do exercício contínuo de interações e conexões estabelecidas. Esses múltiplos fatores retiram a liderança de seu costumeiro local solitário para lançá-la na complexidade das relações interpessoais e interorganizacionais e das inúmeras relações resultantes desse processo (CABRAL; SEMINOTTI, 2009b).

DeRue e Ashford (2010) colocam que a liderança como um processo social desenvolve-se a partir de três elementos chave: a) a internalização individualizada do poder pelo líder; b) o reconhecimento relacional do líder pelo grupo que ele lidera e c) o endosso institucional, ou seja, o espaço de autoridade que a organização valida a cada líder. Dessa forma, a liderança é uma identidade compartilhada entre os envolvidos, que vai e volta em um fluxo dinâmico e contínuo.

As competências e habilidades do líder devem ser compreendidas para além das particularidades do gestor e pelo poder outorgado pela hierarquia, dentro de um contexto que abarca diferentes lugares de ação. Assim, a liderança não deve ser considerada o resultado de elementos isolados, mas uma combinação de perspectivas relacionais e individuais, incluindo agentes internos e externos à organização. (CABRAL; SEMINOTTI, 2009b).

Essa visão amplia também o escopo de tomar a liderança como a capacidade de influenciar, para pensá-la como a "capacidade de vivenciar e propiciar influências recíprocas entre as pessoas; a capacidade de influenciar pessoas lideradas e se deixar influenciar por estas" (CABRAL; SEMINOTTI, 2009b, p. 3), marcando uma relação de interdependência, e inserida na cultura organizacional, onde é construída e se constrói concomitantemente, por meio dos sentidos que são produzidos nas conexões e movimentos processados na rede estabelecida entre "líder-liderados, liderados-liderados e líderes-líderes" (CABRAL; SEMINOTTI, 2009b, p. 3).

A desconstrução da concepção líder-herói contribui para um olhar menos excludente e de valorização da diversidade, na qual atuam variados atores que compartilham informações, valores organizacionais e individuais. Ultrapassar a visão unilateral é tornar a liderança um exercício de flexibilidade, escuta e construção conjunta. O líder sai de um lugar de distanciamento para se apropriar da realidade da organização, combinando o papel de gestor e líder, que atuam de forma complementar e contingencial (CABRAL; SEMINOTTI, 2009a; CABRAL; SEMINOTTI, 2009b; KETS DE VRIES, 1997).

Essa abordagem permite, também, a reflexão sobre a participação das mulheres em cargos de liderança, pois, até então, a predominância do estereótipo masculino na concepção do perfil do líder pouco dava espaço para se pensar os diferentes perfis que abarcam o exercício desse papel. Pensar a liderança em um prisma de coletividade inclusive valoriza a capacidade de acolhimento, escuta e empatia no exercício da liderança - atributos até então, mais comumente vinculados ao comportamento feminino. 


\section{REPRESENTAÇÕES SOCIAIS E GÊNERO: A TRAJETÓRIA DA MULHER NO MERCADO DE TRABALHO}

Segundo Colling (2004) e Strey $(1998,2000)$, as discussões em relação ao gênero se modificaram ao longo do tempo, tanto pela evolução do feminismo como pelas mudanças sociais e comportamentais perceptíveis no entorno social. Assim, diferentemente da questão de diferenciação sexual determinada pelas condições biológicas e fisiológicas, a dimensão do gênero é construída socialmente, determinada pela socialização e o contato com diversas circunstâncias simbólicas socioculturais e históricas. Nesta linha, "o gênero está de acordo com as imagens do que cada um deve ser, construído em cada sociedade e em cada época” (STREY, 1998, p. 183).

A construção social do gênero é marcada, notadamente na civilização ocidental, por um modelo hierárquico patriarcal, que associa o poder a atributos masculinos, reforçando ideologicamente a submissão e discriminação das mulheres. Essas razões traduzem-se de formas variadas em diferentes culturas e são perpetuadas por crenças e paradigmas, dentre elas, as diferenças relacionadas às oportunidades no mercado de trabalho (STREY, 1998).

De acordo com Costa (2010), a função de reprodutora da espécie, que cabe à mulher, favoreceu a sua subordinação ao homem. A mulher foi sendo considerada mais frágil e incapaz para assumir a direção e chefia do grupo familiar. O homem, associado à ideia de provedor e de autoridade, assumiu o poder dentro da sociedade.

Betts (2000) entende que o século XX transformou o destino e identidades de homens e mulheres, com um considerável declínio da potência paterna que até então organizava a sociedade. Através da revolução democrática, a mulher assume um papel de cidadã e de sujeito, abrindo a oportunidade de reinventar sua posição perante os imperativos sociais. Essa nova postura marca transformações profundas, sob uma perspectiva pluralista e menos hierarquizada. Segundo o autor, enquanto a sociedade industrial acentuava os limites entre casa e trabalho e valorizava os atributos físicos masculinos, a sociedade da informação centra-se na importância intelectual, modificando a conjuntura social e profissional das mulheres.

Assim, as mulheres têm enfrentado, ao longo da história, significativas dificuldades no mercado de trabalho. Essas dificuldades encontram-se notadamente marcadas pela ausência de equidade, tanto na participação, na baixa qualidade das posições ocupadas, quanto nas desigualdades de remuneração recebidas em relação aos homens. Como nos afirma Vries (2012), as mulheres necessitam de igualdade factual e não apenas igualdade simbólica.

A participação da mulher no mercado de trabalho, de um modo geral, tem se ampliado nos últimos anos, constatada pelo crescimento do número de mulheres com vínculo empregatício formal em vários níveis, apesar de ainda inferior aos percentuais masculinos, e um destaque da mulher no contexto econômico familiar. No que se refere à remuneração, verificou-se que as mulheres ganham em torno de $72,3 \%$ do rendimento recebido pelos homens, mesmo quando se toma por base um grupo homogêneo, composto com pessoas de mesmo nível de escolaridade e segmento. (IBGE, 2010). De acordo com a PNAD 2015, o rendimento médio mensal real de todos os trabalhos dos homens de 15 anos ou mais de idade, com rendimento de trabalho, foi de R\$ 2058 e o das mulheres, R\$ 1567 . Em termos proporcionais, as mulheres receberam, em média, 76,1\% do rendimento de trabalho dos homens em 2015, o que representou um aumento de 1,6 ponto percentual em relação a 2014, quando essa proporção foi de 74,5\% (IBGE, 2016). 
Hanashiro (2005) e Tanure, Neto e Andrade (2010) mostram que as mulheres que alcançaram posições gerenciais estão concentradas em cargos de terceiro escalão, e ainda assim em percentuais inferiores aos masculinos, conforme pode ser visualizado a seguir:

Tabela 1 - Distribuição dos níveis hierárquicos por gênero

\begin{tabular}{c|cccc}
\hline Nível & Executivo & Gerencial & Chefia & Funcional \\
\hline Masculino & 91,0 & 82,0 & 72,0 & 65,0 \\
Feminino & 9,0 & 18,0 & 28,0 & 35,0 \\
\hline
\end{tabular}

Fonte: Instituto Ethos (2004 apud HANASHIRO, 2005).

Bruschini, Ricoldi e Mercado (2008), também comentam o fenômeno "teto de vidro", barreira que impede mulheres de alcançarem posições de comando devido à segregação ocupacional. Os autores dissertam sobre o elevado preço social pago na busca de espaços de destaque, citando como exemplo as brasileiras, que tendem a casar mais tarde ou permanecer solteiras, limitar o número de filhos e retardar a vinda do primeiro.

Aceder a postos de alto nível é muito mais fácil para os homens do que para as mulheres, mesmo quando eles estão menos bem preparados do que elas. O fosso entre a proporção de mulheres com treino e formação profissional adequados e aquelas que atingem posições de proeminência nas organizações é elevado. Todos os dados indicam que o número de mulheres decresce progressivamente conforme se ascende aos mais altos niveis da hierarquia. E, mesmo quando as mulheres chegam a ocupar postos de liderança, é frequente que seja em setores de atividade econômica tradicionalmente femininos (NOGUEIRA, 2006, p. 58).

Quanto a posições executivas em conselhos de administração, alguns países começaram a criar regras compulsórias para a participação da mulher, como forma de normatizar a promoção à diversidade. No Brasil, de um total de 2.647 posições de conselho em maio de 2011, 7,71\% eram ocupadas por mulheres em companhias listadas. Apesar de o Brasil ocupar uma posição intermediária em relação a outros países, estima-se que mais de $65 \%$ das empresas listadas não possuem nenhuma mulher em seus conselhos (IBGC, 2011).

\section{LIDERANÇA FEMININA NAS ORGANIZAÇÕES}

Betiol e Tonelli (1991), Carreira et al. (2001) e Capelle, Melo e Souza (2013) acreditam que o eixo para entender a problemática do gênero encontra-se no sistema patriarcal, responsável por uma maior valorização dos homens, que é transmitida pelas gerações, cristalizando papéis diferenciados e estanques na sociedade. Algumas mulheres ainda são submetidas a uma educação que estimula a "busca de aprovação social, o controle da agressividade, o medo do conflito, a passividade, a maior restrição ao espaço privado, e a visão do poder como algo externo e distante" (BETIOL; TONELLI, 1991, p. 14). 
Como postula Lobos (2002, p. 50), “a vocação de servir fez da mulher o protótipo do não líder”. Esses estereótipos e esquemas mentais estruturam-se em práticas cotidianas de forma muitas vezes imperceptível, por meio de ideias preconcebidas que atribuem habilidades e competências de acordo com o sexo, cor da pele, idade e outros atributos externos para homens e mulheres. Percebe-se uma tendência em associar inteligência, força física, discernimento e capacidade de decisão ao masculino, e, em contrapartida, entender as mulheres como afetivas, calmas e indecisas. Essas concepções excluem a dinâmica existente na constituição humana, engessam o desenvolvimento e dificultam a ascensão à educação e a conquistas profissionais pelas mulheres, além de negarem os importantes pressupostos contemporâneos de liderança que se baseia no compartilhamento, na inter-relação e em seu caráter facilitador e servidor (CARREIRA et al., 2001; LUCAS et al, 2010; STREY, 2000).

Esses padrões de pensamento reforçam os espaços destinados a cada um dos gêneros, e a bifurcação das competências de gestão em um estilo feminino e um estilo masculino de liderar faz com que, em alguns casos, se espere da mulher a adoção de comportamentos tidos como masculinos, por serem considerados por algumas organizações como mais racionais, objetivos e produtivos (LOMBARDI, 2008). De acordo com Seabra e Muszkat (1987), durante muito tempo, as mulheres assumiram e se identificaram com os papéis a elas atribuídas, perpetuando esses papeis no espaço social. Aos poucos, porém, algumas mulheres sentiram a vontade de resgatar sua identidade e lutar contra a desvalorização sentida. Apesar disso, essa luta, muitas vezes, tem resultado em um embotamento da afetividade, desvalorização das atividades maternais e domésticas e uma supervalorização das atividades profissionais e econômicas. A unilateralidade acabou por tirar a mulher do lugar de passividade para um lugar de negação da identidade, demarcando um repúdio pelo feminino.

Segundo Lombardi (2008), quando isso não acontece e a mulher opta por conservar suas características intrínsecas, ela pode ser levada a comprovar constantemente sua competência, principalmente quando tem homens como subordinados.

Além disso, o que se percebe é que, quando as mulheres resolvem se dedicar à profissão, surgem sentimentos de culpa, na medida em que funda uma duplicidade de papéis. De um lado, é responsabilizada por cuidar da prole, assumir um papel maternal e tradicional; de outro lado, enquanto profissional, é cobrada para ser competitiva, realizadora e prática. Desse modo, as mulheres podem sentir-se discriminadas por si próprias (CARREIRA, 2001; CAPELLE; MELO; SOUZA, 2013; TANURE; NETO; ANDRADE, 2010).

Assim, pensar a mulher no mercado de trabalho e nos postos de liderança implica considerar, para além dos indicadores de participação nos cargos de gestão, como essas trajetórias estão sendo construídas, como essas mulheres percebem as demandas sociais e como estas atuam como agentes transformadores de sua identidade. Implica ultrapassar visões feministas e machistas ou preceitos de igualdade entre os sexos, para encontrar maneiras de liderar que respeitem características e qualidades de homens e de mulheres. Isso não significa dizer que a luta pela igualdade não é fundamental, mas esta deve levar em conta a diversidade existente no universo feminino e não perder de vista que os direitos só estarão garantidos à medida que estiverem legitimados na subjetividade feminina e masculina, a partir de uma reconfiguração desses papéis socialmente e culturalmente. 


\section{METODOLOGIA}

Esse artigo reflete uma pesquisa de campo qualitativa e exploratória, de caráter transversal, que teve como estratégia de coleta de dados a entrevista narrativa. $\mathrm{O}$ delineamento qualitativo se define por uma abordagem que envolve os processos implicados na percepção dos sujeitos emergentes da discussão de suas experiências. Assim, "não se buscam regularidades, mas a compreensão dos agentes, daquilo que os levou singularmente a agir como agiram". (GODOI; BANDEIRA-DE-MELLO; SILVA, 2010, p. 91). Tratase de ouvir tais sujeitos dentro de sua lógica e razões, situando-os dentro de seus sistemas sociais, em uma perspectiva de interpretação de sentidos difusos que se encontram nas crenças, valores e no imaginário social.

O tratamento dos dados deu-se pelo uso do software de categorização de dados Nvivo e análise de discurso da escola francesa (PÊCHEUX, 1988). Como enfatiza Orlandi (2000), a análise de discurso não se trata de linguística nem tampouco da gramática, mas sim do discurso, compreendendo seu sentido construído ao longo da história dos sujeitos. A análise de discurso concebe a língua como algo em movimento, na relação entre a história e a linguagem, através da posição que ocupa em uma determinada estrutura de formação social. Assim, ao usar a linguagem o sujeito o faz a partir de recortes conceituais produzidos em um contexto amplo, que abarca elementos sócio-históricos e ideológicos.

A coleta de dados foi desenvolvida por meio de entrevistas narrativas com cada uma das cinco executivas de alta gestão. Ao todo foram realizadas 08 entrevistas. Em relação ao perfil das entrevistadas, seguem as informações no quadro a seguir:

Figura 1- Caracterização das participantes

\begin{tabular}{c|lccccc}
\hline & \multicolumn{1}{|c}{ Cargo } & Idade & $\begin{array}{c}\text { Estado } \\
\text { civil }\end{array}$ & $\begin{array}{c}\mathrm{N}^{\circ} \text { de } \\
\text { filhos }\end{array}$ & Formação & $\begin{array}{c}\text { Segmento de } \\
\text { Atuação }\end{array}$ \\
\hline E1 & CEO & 54 anos & Separada & Dois & $\begin{array}{c}\text { Doutorado em Relações } \\
\text { Internacionais } \\
\text { Graduação em } \\
\text { Administração }\end{array}$ & $\begin{array}{c}\text { Tecnologia da } \\
\text { Informação } \\
\text { ONG }\end{array}$ \\
E3 & Presidente & 68 anos & Casada & Dois & $\begin{array}{c}\text { Especialização em } \\
\text { Psicologia Escolar }\end{array}$ & Brigada \\
E4 & Comandante & 45 anos & Casada & Dois & Militar \\
E5 & Vice-Presidente & 36 anos & Solteira & Sem & Mestrado em & Metal- \\
& Prefeita & 29 anos & Solteira & Sem & Graduação em Direito & Órgão Público \\
\hline
\end{tabular}

Fonte: Elaboração própria (2016) 


\section{ANÁLISE E DISCUSSÃO DOS RESULTADOS DA PESQUISA}

A transcrição e posterior categorização das entrevistas no software NVivo fez emergir três principais categorias, nomeadas como trajetória, ambiente organizacional e liderança. Na sequência, buscou-se a compreensão do sentido nos discursos tecidos pelas entrevistadas.

Figura 2 - Categorias e subcategorias de análise
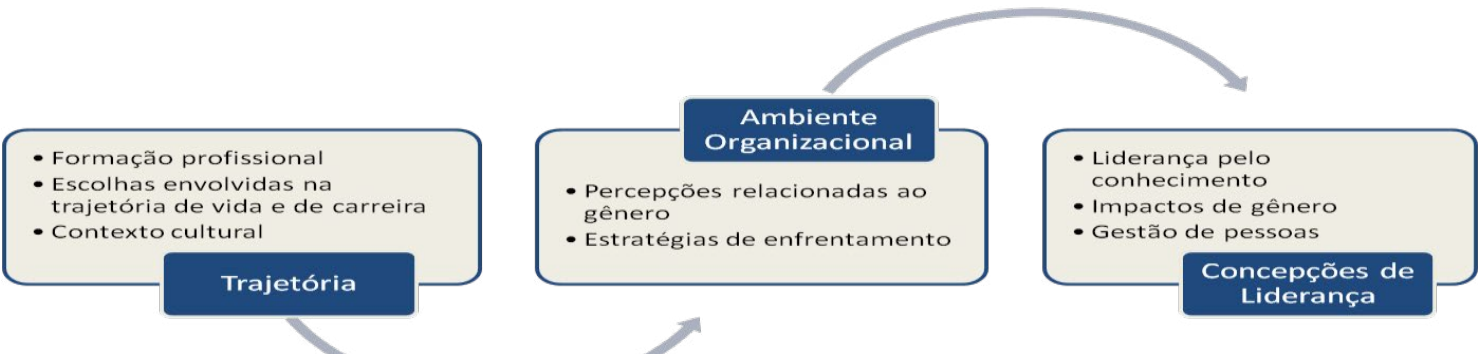

\subsection{Trajetórias}

Essa categoria englobou os aspectos que trataram do percurso de vida e de carreira das mulheres entrevistadas, objetivando-se especialmente entender como foram construídas as suas histórias até chegar ao posto de liderança atual. Assim, buscaram-se elementos no contexto familiar e cultural, as opções profissionais realizadas e os impactos que causaram na vida e perfil dessas mulheres.

Um dos pontos comuns que se pode identificar nas trajetórias das executivas é a relação ao contexto familiar narrado. Percebe-se claramente que quatro das cinco entrevistadas tiveram identificação com uma figura masculina que serviu de referência para os caminhos profissionais traçados, como é o caso das entrevistadas 3 e 4, que respectivamente, afirmaram: "Meu pai era brigadiano, meu vô, meus tios, a família toda de brigadianos"; "Eu vinha de uma família de mecânicos e fui fazer Mecânica né?". Entende-se que isso se deve, em parte, pela recente participação das mulheres no mercado de trabalho, o que faz com que as entrevistadas careçam de referências profissionais femininas.

Em relação ao contexto familiar e social, identificam-se elementos para pensar as primeiras demandas percebidas por essas mulheres a respeito do papel feminino na família e na sociedade a que pertencem. Essas ideias podem ser vistas na fala da entrevistada E4:

"Fui criada, a minha mãe já trabalhou, com uma filosofia que não tem nenhuma diferença entre homens e mulheres (...) às vezes em pessoas antigas, meninos sabem bem matemática e meninas sabem bem outras coisas, ou emocionais. A minha mãe desde pequenininha mostrava que não tem nenhuma diferença". 
Esse recorte vem ao encontro do que foi abordado por Betiol e Tonelli (1991) e Strey (1998), quando trazem o sistema patriarcal como norte para entender a problemática do gênero e que desde cedo diferencia os papéis na sociedade, geralmente colocando a mulher em papéis relacionados a deveres domésticos e aos homens o papel de provedor da família.

Nesse ponto, a entrevistada E1 relata que desde cedo suas escolhas apresentaram uma quebra de paradigma na família e no contexto social em que estava inserida.

“(...) de um lado por primeiro não ter nenhuma mulher então tinha uma aposta nisso tudo dentro da própria escola né, era um desafio muito grande, mas pra mim hoje o Liberato representa não só tecnicamente, mas também um divisor de águas".

Nessa mesma linha, os estereótipos sociais também não passaram despercebidos pelas mulheres participantes da pesquisa. Essa ideia pode ser representada pelo fragmento do discurso da entrevistada E3 quando diz:

“(...) a casa né, isso é histórico, é geracional, é cultural né, é vivendo assim um estado machista, em que as mulheres sempre tiveram a retaguarda né, sempre no completamento da família e nunca no par a par. (...) desde a era primitiva as mulheres sempre foram tidas como objeto, como propriedades, como seres submissos, subjugadas e isso não é dizimado de um dia pro outro né, ainda vai anos ainda né, pra que a gente tenha direitos iguais né, por mais que a constituição nos diga que nós temos direitos iguais".

Esse enunciado está ligado à representação que os sujeitos têm dos outros sujeitos e atuam como mecanismos de funcionamento discursivo, relacionados às imagens resultantes de suas projeções em relação ao imaginário de como a sociedade a percebe e atuando como memória discursiva.

Dentro desse cenário, vale ainda destacar o papel de pioneirismo identificado na trajetória da maioria das entrevistadas. Todas foram, de alguma forma, primeiras em suas atividades no contexto a que pertencem, e sem dúvida, esse fato gerou expectativas diversas nelas, já que se sentiram muitas vezes responsáveis pelo caminho traçado por elas e para as mulheres que se seguiriam.

O pioneirismo e o desejo de fazer diferença no contexto a que pertencem, somado ao sentimento de responsabilidade e à vontade de se destacar no caminho que estava sendo percorrido, contribuiu também para incentivar o empenho em suas formações profissionais, pois todas buscaram na qualificação profissional e no conhecimento a chave para alcançar as posições de destaque em suas áreas de atuação, mesmo diante de dificuldades, sendo exigidas a realizar determinadas escolhas e estando conscientes das implicações pessoais que as mesmas acarretariam, como aponta a E3 
"se tu fizeres um bom trabalho, tu tem a expectativa, tu dá a esperança para que

outras mulheres também se projetem 'ó dá certo', 'eu posso'e que também no mundo masculino acredite 'ó, as mulheres também conseguem'”.

Também podem ser percebidos no discurso das participantes os impactos da mobilidade em suas vidas familiares, como pode ser percebido em vários momentos da fala de grande parte das entrevistadas, tais como a da participante E1 a seguir:

“(...) fiz uma especialização, voltei algumas vezes né, e fiz um ano, dai voltei pro Brasil (...) fiquei seis meses ganhei uma bolsa para um doutorado dai sai de novo fui pra Espanha, dai também o casamento foi, foi-se embora com tudo isso (...) eu tive que assumir toda a família né, eu tive que pegar meus dois meninos e tudo".

Aqui são destacadas as dificuldades de mobilidade vivenciadas pelas mulheres, e que impactam diretamente a vida familiar e profissional. Essa dificuldade refere-se ao estereótipo cultural que ainda visualiza a mulher próxima às atividades domésticas, inclusive geograficamente, responsável pelo cuidado dos filhos e que marca o enunciado dos sujeitos. Esse ponto é bem visível nesse fragmento, notadamente na segunda parte, demonstrando as implicações que a mudança trouxe para a vida matrimonial e familiar e a consequente sobrecarga ao se responsabilizar pelo cuidado dos filhos.

Ainda em relação às implicações familiares e pessoais, das três entrevistadas que são mães, duas relataram impactos consideráveis em relação à maternidade e dificuldades vivenciadas para conciliar as escolhas profissionais com a participação na vida dos filhos, inclusive relatando sentimentos de culpa.

Conforme Carreira (2001), Tanure, Neto e Andrade (2010) e Vries (1997), no Brasil, devido a questões culturais, a progressão das mulheres no mercado de trabalho não se traduziu em um significativo compartilhamento das responsabilidades em relação aos filhos e muitas vezes interferindo na relação com o parceiro amoroso também. As questões relacionadas à autocobrança e aos sentimentos de culpa também são presentes na medida em que a duplicidade de jornada dificulta uma maior participação na vida dos filhos e gera ora uma sobrecarga emocional, ora a postergação da maternidade por parte de muitas executivas.

Mas, mesmo com essas dificuldades, as duas entrevistadas mães encontraram estratégias para administrar esses impasses, como podemos ver no fragmento do discurso da entrevistada E1 que se segue:

“(..) quanto mais eles avançavam na idade né, meus filhos começaram a perceber que aquilo não era uma ausência e começaram a valorizar quem eu era né, como mãe, como profissional (...) uma mãe que tem um lado profissional importante, que tá entregando coisas (...) começou a mitigar a questão da culpa quando eu comecei a ver que isso tava surgindo, porque isso não era simplesmente um elogio pra mãe, não era isso, mas era uma criação de valor pra eles né, era o valor do trabalho, o valor que tem que ter determinado sacrificio". 
Nota-se aqui a importância que teve para a entrevistada demonstrar aos filhos o sentido da trajetória traçada, como forma de resgate e de certa forma uma reparação do sacrifício realizado e o entendimento dos mesmos para além do papel de mãe, mas sim como uma profissional, demarcando o lugar no qual a entrevistada quer ser reconhecida.

Esse ponto vem ao encontro do que salientam Tanure, Neto e Andrade (2010) ao afirmar que o número de mulheres no topo da carreira que não têm filhos é bem maior que o percentual de homens e que muitas vezes isso vem da própria dificuldade de negociar a divisão de tarefas com os cônjuges. Mesmo assim, segundo demonstra a referida pesquisa, as executivas que conseguiram alcançar o topo sentem-se satisfeitas, gostam do que fazem e não abandonariam a carreira para se dedicar mais à família.

\subsection{Ambiente organizacional}

Essa categoria trata das percepções em relação ao ambiente organizacional, dividido em dois grandes escopos de análise: percepções relacionadas ao gênero e estratégias de enfrentamento, buscando compreender como as participantes da pesquisa percebem o fato de serem mulheres no mundo do trabalho e como enfrentaram os eventuais impasses vivenciados, notadamente no que diz respeito à empregabilidade, aos "tetos de vidro" e aos estereótipos de gênero.

Em relação ao cenário empresarial, segundo algumas participantes, as empresas tiveram que se adaptar à chegada das mulheres, pois a cultura ainda é marcadamente masculina, conforme narra a entrevistada E3:

"A entrada das mulheres na Brigada foi uma necessidade pela mudança no tempo, a Brigada de uma certa forma se sentiu né 'opa e agora o que vamos fazer o que com essas mulheres' tipo, tem que ter um... ter alojamento só pra elas, tem que ter banheiro pra elas e os quartéis não estavam preparados pra isso".

Nesse caso, novamente pode ser percebido que os enunciados remetem à historicidade do papel da mulher na sociedade. Assim, de acordo com essa perspectiva, a identificação com determinados saberes instituídos socialmente se inscreve em dada formação discursiva, passando de empírico para discursivo e demarcando o lugar que o sujeito ocupa na sociedade.

Ao relatarem suas percepções sobre o contexto organizacional, as participantes não relataram nenhuma situação de discriminação vivenciada, mas reconhecem dificuldades relacionadas ao gênero. Isso se deve, em parte, segundo E4, à baixa concentração de mulheres em áreas tradicionalmente masculinas, que fazem com que a presença delas em determinados ambientes não seja vista com normalidade.

Quanto às dificuldades relatadas, ainda percebem uma desvalorização, ilustrada neste fragmento de E4: “(...) em reuniões e né, quando tu dá um algum... tu dá alguma sugestão e o outro dá a sugestão, ah sugestão foi dele, porque como né, sugestão do homem". 
Outro ponto que merece destaque em seus discursos é a necessidade de comprovação sistemática da capacidade técnica e de gestão, comentados por Lombardi (2008) e Nogueira (2006) e comprovado nas entrevistas, conforme pode ser visualizado quando E3 diz:

"Tem que cuidar bem mais né, de não errar, os seres humanos são passíveis de erros, e ai tu tem que cuidar mais que homem, porque se a cobrança pra um homem é $X$, pra uma mulher é $X+1$ né, porque ela tem que provar que ela é melhor ainda (...) a cobrança apesar dos homens dizerem que não tem, sempre tem, sempre tem assim, aquela, aquela entrelinha que tu saca”.

Quanto à questão da "masculinização" citada por Tanure, Neto e Andrade (2010), a CEO E1 também marca essa questão, visualizada na passagem a seguir:

“(...) você segue sendo uma mulher né, então sendo uma mulher né, é como você não deixar de ser ou de poder usar saia, usar uma maquiagem mas sem é ir pro demais pro lado do uso né da sexualidade como a gente sabe que ainda existe".

\subsection{Liderança}

A categoria abrange os aspectos relacionados aos papeis de liderança desempenhados, de forma a identificar o lugar no qual essas líderes se situam.

Em todas as entrevistadas percebeu-se a importância dada ao conhecimento e qualificação técnica como forma de consolidar o papel de liderança e, também em parte, pela necessidade de comprovar constantemente suas competências, conforme já comentado anteriormente. Isso pode ser percebido no discurso de E3, quando comenta:

"Tem que ir aos poucos né, muito seguro né passando por todas as etapas de acertos e de erros né, pra quando chegar num momento de liderança (...) tem que saber fazer, principalmente as mulheres né, primeiro tem que saber fazer a coisa né, ninguém vai saber como dizer pra uma faxineira como limpar bem um banheiro se nunca limpou".

Cabe ressaltar aqui que a entrevistada usa como exemplo uma atividade que historicamente relaciona-se ao papel da mulher, demarcando ainda a presença da questão ideológica em sua formação discursiva.

Essa valorização pela própria capacidade técnica, e em contrapartida pela capacidade técnica da equipe, demarca um estilo compartilhado de liderança e focado nas pessoas, conforme podemos comprovar quando a entrevistada E4 fala: 
"Eu sou da área financeira, eu conheço melhor finanças, balanço que meu gerente de controladoria, mas menos que meu gerente de finanças. Eu preciso ter um conhecimento um pouco de tudo, mas conhecimento de especialista nessa linha particular, eles precisam saber melhor do que eu. Eu tenho expectativa que meus gerentes saibam melhor do que eu das áreas particulares".

Nota-se ainda nesse fragmento a relação de rede estabelecida com os liderados, onde todos compartilham informações e geram um aprendizado coletivo. Além disso, as entrevistadas referem-se ao aspecto instrumental da gestão, que deve atuar dialogicamente e recursivamente com o papel relacional da liderança, para a eficácia de seu desempenho (CABRAL; SEMINOTTI, 2009b).

E2, na sua definição de liderança, fala que a liderança com "L" maiúsculo implica responsabilidade permanente, um projeto de vida que visa o desenvolvimento da organização e das pessoas, como salienta na fala a seguir:

“(...) por isso é que se diz que a liderança é uma coisa solitária, porque por mais que um líder tenha um grupo de pessoas, que é a organização, uma empresa que tem a sua governança,(...) aquela liderança, numa decisão final, ela está sozinha (...) pra ti ser líder acho que tu precisa gostar daquilo que faz, ninguém é líder daquilo que não gosta né, tem que ter uma... gostar muito daquilo, tem que ter uma vocação, tem que tá imbuída daquela missão, de que aquilo que tu estás fazendo é uma coisa importante".

Cabe ressaltar aqui a visão da entrevistada ainda bastante relacionada a pressupostos de lideranças ligados ao líder-herói, aquele imbuído de uma missão, dotado de uma capacidade diferenciada e em um local de isolamento. Como vimos anteriormente, essa visão ainda carrega em si preceitos fundamentalmente masculinos construídos ao longo da história. (BRYMAN, 2012; CAVALCANTI et al., 2006; CABRAL; SEMINOTTI, 2009a).

\subsection{Discussão integrada dos dados}

Com o intuito de identificar palavras recorrentes nos discursos das entrevistadas, utilizou-se o software NVivo, que, através de uma ferramenta de mensuração de frequência com base nas transcrições das entrevistas. Assim, o quadro a seguir foi gerado desconsiderando vocábulos com menos de três letras, com o intuito de focar as palavras que contêm algum significado para a análise almejada e servissem como base para corroborar alguns dos pontos que estão sendo desenvolvidos. 
Quadro 1 - Frequência das palavras nas entrevistas

\begin{tabular}{|l|l|}
\hline \multicolumn{1}{|c|}{ Palavra } & \multicolumn{1}{c|}{ Contagem } \\
\hline Pessoas & 140 \\
\hline Acho & 134 \\
\hline Gente & 105 \\
\hline Mulher & 84 \\
\hline Trabalhar & 76 \\
\hline Mulheres & 75 \\
\hline Trabalho & 67 \\
\hline Incompreendido & 66 \\
\hline Pessoa & 57 \\
\hline Empresa & 56 \\
\hline Organização & 49 \\
\hline Liderança & 34 \\
\hline Mãe & 31 \\
\hline Exemplo & 30 \\
\hline Homens & 30 \\
\hline Família & 29 \\
\hline Homem & 29 \\
\hline Conhecimento & 28 \\
\hline Casa & 27 \\
\hline
\end{tabular}

O primeiro ponto a salientar é a frequência da enunciação da palavra "pessoas", atingindo o primeiro lugar da lista, mesmo sem considerar a frequência do vocábulo no singular. Isso demonstra o foco nas pessoas comentado anteriormente, fato que justificou a emergência de uma subcategoria de análise dentro do tema da liderança. Pode-se perceber também que as palavras "mãe", "família" e "casa", foram menos frequentes que "trabalho", "empresa", "liderança" e "organização", demarcando o lugar de fala dessas mulheres.

Para finalizar, cabe ainda sinalizar alguns aspectos a serem considerados pelas organizações e pelas mulheres no que tange à sua maior participação no mercado de trabalho e nos postos de liderança. Esse ponto é abordado por duas das entrevistadas, que falam da importância das empresas darem subsídios e condições para facilitar a retenção e maior desempenho feminino em suas atividades profissionais. A respeito disso a $\mathrm{CEO}$, que é a entrevistada E1, conta que em sua trajetória

“(...)no mínimo dois dias eles passavam junto comigo dentro da CNI, então, isso era importante pra eles entender um pouquinho o pique que eu tava envolvida com aquele trabalho meu né, porque que eu tinha tanta demanda, porque eu tinha que viajar, porque que né, então esse entendimento, essa coisa de trazer eles pra perto de mim né, no meu trabalho também ajudou bastante". 
A entrevistada E4 fala que a empresa na qual trabalha atualmente possui atividades que são destinadas para mulheres, especialmente por suas habilidades diferenciadas, mas admite que ainda não há ações voltadas especificamente para o desenvolvimento de lideranças femininas. Mesmo assim, reconhece a importância de facilitar a conciliação da vida pessoal e profissional, especialmente no que tange à maternidade e o regresso da mulher ao mercado de trabalho após ser mãe, falando que

“(...) muitas empresas têm creches dentro da empresa, e com isso uma mulher fica muito mais tranquila. Imagina você chega de manhã na empresa, deixa ali e vai trabalhar. Você está sabendo que se tiver algum problema, vomitando ou não sei o que, você fica 5 minutos e poderá checar se está tudo bem. Isso deixa a mulher muito mais tranquila. Isso eu acho uma medida muito eficaz para retenção".

Nesse sentido Lucas et al. (2010) dizem que cada empresa deve tratar a questão da diversidade de gênero de maneira adequada à cultura e peculiaridades da organização, não havendo uma "receita" de políticas aplicáveis a todas as realidades. Dentre as principais práticas, os autores salientam que em sua maioria elas visam o auxílio no desempenho de seus diferentes papéis sociais, de acordo com as necessidades de homens e mulheres em termos de saúde, educação e acesso igualitário ao crescimento profissional. Nessa linha destacam que é importante reconhecer as diferenças para promover políticas de gestão de pessoas adequadas, fortalecendo as características de cada pessoa e evitando estereótipos.

\section{CONSIDERAÇÕES FINAIS}

Percorrendo a análise de discurso das entrevistadas, primeiramente percebe-se a presença de um modelo masculino em suas vidas familiares e sociais, que marcou suas trajetórias, de uma forma ou de outra. Isso se percebeu principalmente quando dissertavam sobre o tradicional papel das mulheres em nossa sociedade, geralmente não associado à gestão e à liderança. Cabe destacar ainda, o pioneirismo no ambiente masculino percebido em todas as gestoras do estudo, demonstrando a incipiente participação da mulher no universo organizacional, especialmente no que diz respeito à ocupação de cargos de alto escalão.

As vivências levaram essas mulheres a terem de romper os estereótipos percebidos, investir fortemente em sua qualificação e aperfeiçoamento técnico e realizar várias escolhas e renúncias para dar conta dos desafios encontrados. Em grande parte das entrevistadas pode-se perceber impactos em sua vida familiar e pessoal e a necessidade de uma organização capaz de conciliar esses dois polos. Destaca-se ainda que, apesar de, em um primeiro momento, as entrevistadas mães negarem sentimentos de culpa pela exigência de uma carga horária relevante para dedicar-se às atividades profissionais.

Em relação ao contexto organizacional, apesar de primeiramente apresentar uma negação em relação à discriminação de gênero, quatro das cinco entrevistadas relataram dificuldades nesse âmbito. Dentre as situações relatadas, merece destaque as que estão relacionadas à exigência de sistematicamente terem que comprovar suas competências, e ao nível de cobrança sofrido, diferente dos homens. Assim, admitem que os erros das mulheres têm um peso maior no contexto organizacional, justamente por estarem em um momento de conquista de seus espaços. Assim, a cobrança e as exigências não pairam apenas no próprio desempenho, mas no que este impacto no caminho trilhado pelas mulheres como um todo. 
Como resultado, percebe-se a tendência a assumir uma postura peculiarmente masculina no ambiente de trabalho, para serem reconhecidas no papel de liderança, percebido em expressões relacionadas a necessidade de impor limites, não demonstrar fraquezas, falar de igual para igual, entre outras. Além disso, foi unânime a necessidade de se firmar pelo conhecimento e domínio técnico das áreas a serem lideradas, para sustentar a posição de liderança, o respeito e o reconhecimento no contexto a que pertencem.

Mas, apesar das dificuldades, a forma de liderarem tem um foco bastante marcante nas pessoas a seu redor, valorizam as individualidades, compartilham decisões e pontos de vista com flexibilidade. Mesmo em ambientes adversos, consideram a responsabilidade de seu papel em relação às outras pessoas, tanto familiares como liderados e estão buscando estratégias para enfrentar os mais diversos impasses vivenciados.

Foi possível perceber que apesar dos avanços relacionados à participação da mulher no mercado de trabalho e em postos de gestão ainda os ganhos são superficiais. Nesse sentido, esse estudo pode contribuir para a ampliação da visão do conceito de liderança e o entendimento de como esses estereótipos sociais são construídos ao longo do tempo, e se traduzem na sociedade e nas culturas organizacionais. Isso permite elencar alguns fatores a serem considerados pelas empresas na construção de políticas e práticas que considerem a trajetória profissional e pessoal das mulheres, e uma ressignificação do papel na sociedade, almejando assim, um maior respeito à sua individualidade e direito de escolha.

Reconhece-se, ao final dessa pesquisa, que muito ainda se tem a avançar no estudo sobre a liderança feminina, e considera-se como limitações da pesquisa o fato de que não foi possível realizar os três momentos da entrevista narrativa com todas as participantes. Para futuras pesquisas, sugere-se um estudo sobre as peculiaridades dos setores em relação à problemática do gênero, como também investigar eventuais parâmetros geracionais que podem influenciar essa realidade. Outra questão a ser trabalhada pode ser a percepção masculina sobre o universo feminino em relação à liderança e participação nos postos de tomada de decisão organizacional.

Para finalizar, cabe citar uma frase falada por uma das entrevistadas e que engloba o universo que compreende a presente pesquisa. Ela traz a ideia de que a mulher deve ter condições de fazer suas escolhas, de acordo com seus sonhos e objetivos e não que elas sejam fruto de pressões e estereótipos de qualquer parte: "Lugar de mulher é? É onde ela quiser".

\section{REFERÊNCIAS}

BELLE, F. A. Executivas: quais as diferenças na diferença? In: CHANLAT, J.F. (org). O indivíduo na organização: dimensões esquecidas. São Paulo: Atlas, v. 2, 2012.

BETIOL, M. I. S.; TONELLI, M. J. As mulheres executivas e suas relações de trabalho. RAE - Revista de Administração de Empresas, São Paulo, v. 31, p. 17-33, 1991.

BRUSCHINI, C.; RICOLDI, A. M.; MERCADO, C. M. Trabalho e gênero no Brasil até 2005: uma comparação regional. In: COSTA, A. O. et al. (Org.). Mercado de trabalho e gênero: comparações internacionais. Rio de Janeiro: FGV, 2008.

BRYMAN, A. Liderança nas Organizações. In: CLEGG, S. R. et al. (Org.) Handbook de estudos organizacionais. São Paulo: Altas, 2012. v. 3.

CABRAL, P. M. F.; SEMINOTTI, N. Competências de liderança e competências gerenciais: um olhar dialógico. In: ENCONTRO ANUAL DA ASSOCIAÇÃO NACIONAL DOS PROGRAMAS DE PÓS-GRADUAÇÃO EM ADMINISTRAÇÃO - EnANPAD, 33., São Paulo. Anais eletrônicos... São Paulo: Associação Nacional de Pós-Graduação e Pesquisa em Administração (ANPAD), 2009a. Disponível em: <www.anpad.org.br/evento.php?acao=trabalho\&cod_edicao_subsecao=506\&cod_evento_ edicao=45\&cod_edicao_trabalho=10967>. Acesso em: 26 mar. 2013. 
CABRAL, P. M. F.; SEMINOTTI, N. A Dimensão Coletiva da Liderança. Caderno IHU Ideias, São Leopoldo, ano 7, n. 120, 2009b. CAPELLE, M. C. A.; MELO, M. C. O.; SOUZA, N. L. Mulheres, trabalho e administração. Revista Interdisciplinar de Gestão Social, Salvador, v. 2, n. 2, p. 161-191, maio/ago. 2013.

CARREIRA, D. et al. Liderança feminina no século 21. São Paulo: Cortez, 2001.

CAVALVANTI, V. L et al. Liderança e motivação. 2. ed. Rio de Janeiro: Editora FGV, 2006.

COLLING, A. M. A construção histórica do feminino e do masculino. In: STREY, M.N.; CABEDA, S.L.; PREHN, D.R. (Org.). Gênero e cultura: questões contemporâneas. Porto Alegre: EDIPUCRS, 2004.

COSTA, Lucia. Gênero: uma questão feminina? [S.1.], 2010. Disponível em: <www.uepg.br/nupes/Genero.htm>. Acesso em: 16 abr. 2013.

DeRUE, D. S; ASHFORD, S. J. Who will lead and who will follow? A social process of leadership identity construction in organizations. Academy of Management Review, v. 35, n. 4, p. 627-647, 2010.

GODOI C. K.; BANDEIRA-DE-MELLO, R.; SILVA, A. B. (Org.) Pesquisa qualitativa em estudos organizacionais: paradigmas, estratégias e métodos. 2. ed. São Paulo: Saraiva, 2010.

HANASHIRO, D. M. et al. Diversidade na liderança: há diferença de gênero? In: ENCONTRO ANUAL DA ASSOCIAÇÃO NACIONAL DOS PROGRAMAS DE PÓS-GRADUAÇÃO EM ADMINISTRAÇÃO - EnANPAD, 29., Brasília. Anais...: São Paulo: Associação Nacional de Pós-Graduação e Pesquisa em Administração (ANPAD), 2005.

INSTITUTO BRASILEIRO DE GEOGRAFIA E ESTATÍSTICA - IBGE. IBGE divulga informações sobre a mulher no mercado de trabalho. 2010. Disponível em: <www.ibge.gov.br/home/presidencia/noticias/noticia_visualiza.php?id_noticia=1567\&id._pagina=1>. Acesso em: 06 abr. 2013.

INSTITUTO BRASILEIRO DE GEOGRAFIA E ESTATÍSTICA - IBGE: PESQUISA NACIONAL POR AMOSTRA DE DOMICÍLIOS - PNAD: síntese de indicadores 2015 / IBGE, Coordenação de Trabalho e Rendimento. - Rio de Janeiro : IBGE, 2016. 108p. Disponível em: http://biblioteca.ibge.gov.br/visualizacao/livros/liv98887.pdf Acesso em: 04 set. 2017.

INSTITUTO BRASILEIRO DE GOVERNANÇA CORPORATIVA - IBGC. Relatório de mulheres na administração das empresas brasileiras listadas - 2010 e 2011. [S.1.], 2011. Disponível em: <www.ibgc.org.br>. Acesso em: 15 de mar. 2013.

VRIES, Manfred F. R. Kets.Liderança nas empresas: como o comportamento do líder afeta a cultura interna. Tradução de Reynaldo Cavalheiro Marcondes e Anna

Christina de Mattos Marcondes. São Paulo: Atlas, 1997.

. Sexo, Dinheiro, Felicidade e Morte: A Busca por Autenticidade. São Paulo: Bookman, 2012.

LOBOS, J. Mulheres que abrem passagem: o que os homens têm a ver com isso. São Paulo: J. Lobos, 2002.

LOMBARDI, M. R. Engenheira e gerente: desafios enfrentados por mulheres em posições de comando na área tecnológica. In: COSTA, A. O. et al. (Org.). Mercado de trabalho e gênero: comparações internacionais. Rio de Janeiro: Editora FGV, 2008.

LUCAS, A. C. et al. Identificação de práticas de gestão voltadas à questão de gênero: um estudo a partir das melhores empresas para você trabalhar. In: ENCONTRO ANUAL DA ASSOCIAÇÃO NACIONAL DOS PROGRAMAS DE PÓS-GRADUAÇÃO EM ADMINISTRAÇÃO - EnANPAD, 34., Rio de Janeiro. Anais...: São Paulo: Associação Nacional de Pós-Graduação e Pesquisa em Administração (ANPAD), 2010.

NOGUEIRA, M. Os discursos das mulheres em posições de poder. Cadernos de Psicologia Social do Trabalho, [S.l.], v. 9, n. $2,2006$.

ORLANDI, E. Análise de discurso: princípios e procedimentos. Campinas: Pontes, 2000.

PÊCHEUX, M. Semântica e discurso: uma crítica à afirmação do óbvio. (trad.) Campinas: Editora UNICAMP, 1988.

STREY, M. N. Gênero. In: STREY, M. N. (Org.). Psicologia social contemporânea: livro texto. 8. ed. Petrópolis: Vozes, 1998. STREY, M. N. Será o século XXI o século das mulheres? In: STREY, M. N. et al. (Org.).Construções e perspectivas em gênero. São Leopoldo: Unisinos, 2000.

TANURE, B.; NETO, A. C.; ANDRADE, J. O. Executivas: carreira, maternidade, amores e preconceitos. RAE Eletrônica, v. 9, n.1, art. 3, jan./jun. 2010. Disponível em: http://rae.fgv.br/rae-eletronica/vol9-num1-2010. Acesso em: 27 mar. 2013.

TURANO, L. M.; CAVAZOTTE, F.. Conhecimento Científico sobre Liderança: Uma Análise Bibliométrica do Acervo do The Leadership Quarterly RAC, Rio de Janeiro, v. 20, n. 4, art. 3, pp. 434-457, Jul./Ago. 2016. 